\title{
Behavioral outcomes of a novel, pelvic nerve damage rat model of fecal incontinence
}

Citation for published version (APA):

Janssen, P. T. J., Breukink, S. O., Melenhorst, J., Stassen, L. P. S., Bouvy, N. D., Temel, Y., \& Jahanshahi, A. (2018). Behavioral outcomes of a novel, pelvic nerve damage rat model of fecal incontinence. Neurogastroenterology and Motility, 30(4), [e13242]. https://doi.org/10.1111/nmo.13242

Document status and date:

Published: 01/04/2018

DOI:

10.1111/nmo.13242

Document Version:

Publisher's PDF, also known as Version of record

Document license:

Taverne

Please check the document version of this publication:

- A submitted manuscript is the version of the article upon submission and before peer-review. There can be important differences between the submitted version and the official published version of record.

People interested in the research are advised to contact the author for the final version of the publication, or visit the DOI to the publisher's website.

- The final author version and the galley proof are versions of the publication after peer review.

- The final published version features the final layout of the paper including the volume, issue and page numbers.

Link to publication

\footnotetext{
General rights Owners
rights.

- You may freely distribute the URL identifying the publication in the public portal. please follow below link for the End User Agreement:

www.umlib.nl/taverne-license

Take down policy

If you believe that this document breaches copyright please contact us at:

repository@maastrichtuniversity.nl

providing details and we will investigate your claim.
}

Copyright and moral rights for the publications made accessible in the public portal are retained by the authors and/or other copyright owners and it is a condition of accessing publications that users recognise and abide by the legal requirements associated with these

- Users may download and print one copy of any publication from the public portal for the purpose of private study or research.

- You may not further distribute the material or use it for any profit-making activity or commercial gain

If the publication is distributed under the terms of Article $25 \mathrm{fa}$ of the Dutch Copyright Act, indicated by the "Taverne" license above, 


\title{
Behavioral outcomes of a novel, pelvic nerve damage rat model of fecal incontinence
}

\author{
P. T. J. Janssen ${ }^{1}$ ｜ S. O. Breukink ${ }^{1}$ | J. Melenhorst ${ }^{1}$ | L.P. S. Stassen ${ }^{1}$ | N. D. Bouvy ${ }^{1}$ | \\ Y. Temel ${ }^{2,3}$ A. Jahanshahi ${ }^{2,3}$
}

${ }^{1}$ Department of Surgery, Maastricht University Medical Centre, Maastricht, The Netherlands

${ }^{2}$ Department of Neurosurgery, Maastricht University Medical Centre, Maastricht, The Netherlands

${ }^{3}$ Department of Neuroscience, Maastricht University, Maastricht, The Netherlands

\section{Correspondence}

Ali Jahanshahi, Department of Neurosurgery, Maastricht University Medical Center,

Maastricht, The Netherlands.

Email: a.jahanshahi@maastrichtuniversity.nl

\begin{abstract}
Background: Fecal incontinence (FI) has a multifactorial pathophysiology with a severe social impact. The most common cause for $\mathrm{Fl}$ is pudendal nerve damage, which mostly occurs in women during or after labor. A better understanding of the pathophysiology is required to optimize treatment of FI. In this study, we evaluate the use of a novel pelvic nerve damage rat model of $\mathrm{FI}$.

Methods: This new model simulates the forces on the pelvic floor during labor by prolonged transvaginal, retro-uterine intrapelvic balloon distention in female rats. Number of fecal pellets produced per day and defecation pattern was compared between the experimental and control group for 2 weeks. The cages of the rats were divided in food, nesting and latrine areas to evaluate changes in defecation pattern. The FI Index (FII) was calculated to assess the ratio of fecal pellets between the nonlatrine areas and the total number of pellets. A higher score represents more random distribution of feces outside the latrine area.

Results: Total number of fecal pellets was higher in the experimental group as compared with the controls. In both groups most fecal pellets were deposited in the nesting area, which is closest to the food area. The experimental group deposited more fecal pellets in the latrine area and had a lower FII indicating less random distribution of feces outside the latrine area.

Conclusion: Transvaginal, retro-uterine intrapelvic balloon distention is a safe and feasible animal model simulating the human physiologic impact of labor by downwards pressure on the pelvic floor.
\end{abstract}

KEYWORDS

fecal incontinence, pelvic nerve damage, rat model

\section{1 | INTRODUCTION}

Fecal incontinence $(\mathrm{FI})$ is a multifactorial problem, with a severe social impact. ${ }^{1}$ Several studies report a prevalence ranging from $7 \%$ up to $15 \%$ in adults that increases with age. ${ }^{2}$ Obstetrical injury is the most common cause for $\mathrm{Fl}^{3,4}$ It is known that pudendal nerve damage is the most common cause for developing fecal incontinence. ${ }^{5,6}$ However, mechanisms of nerve damage remain uncertain. Due to its course through the pelvic floor, this nerve is vulnerable for injury during labor such as traction at the level of the ischial spina, compression in the pudendal canal or avulsions of terminal fibers. ${ }^{7}$

Surgical treatment options for fecal incontinence can be divided into sphincter-restorative procedures, neuromodulation, neosphincter procedures and colostomy. Sphincter-restorative and neosphincter procedures are invasive procedures with low longterm success-rate of $40 \%^{8,9}$ and high complication rate ranging 
up to $42 \% .{ }^{10}$ Sacral neuromodulation (SNM) is a minimal invasive treatment option for $\mathrm{FI}$ with success-rates ranging from $47.7 \%$ up to $54 \%$ based on intention to treat analysis. ${ }^{11-13}$ However, loss of efficacy occurs in up to $40 \%$ of patients treated with SNM. ${ }^{14} \mathrm{~A}$ common hypothesis is that the high rate of loss of efficacy of all treatment options for $\mathrm{Fl}$ is often related to the lack of understanding of the pathophysiology of FI. Thus far, limited preclinical data on the pathophysiology of $\mathrm{FI}$ and associated behavioral changes have been reported. ${ }^{15-17}$ This is mainly due to the lack of reliable animal models in this field of research.

It is known that rats are a coprophagic species ${ }^{18}$ however, both the blind mole rats (Spalax ehrenbergi) and the normal rats are shown to exhibit place preference for its latrine to some extent. ${ }^{19,20}$ In this context, pudendal nerve transection in rats has been evaluated to assess the effect of neuropraxia on the external anal sphincter. ${ }^{16,21}$ Only one previous study has reported an animal model with pudendal nerve damage using retro-uterine balloon distention without traction to the pelvic floor. ${ }^{16}$ The model used an abdominal approach to place two retro-uterine catheters. Because the catheters were not fixated, it is debatable whether the correct pressure, comparable to labor condition was applied on the pelvic floor.

Here, we introduce a new animal model to study FI using objectified compressive forces on the pelvic floor that mimics the physiological pressure on the pelvic floor during vaginal delivery. We adapted a technique which was previously described by Sievert et al, to evaluate lower urinary tract after delivery in rats. ${ }^{22}$ However, this previous model used intravaginal balloon dilation, whereas we adapted this to transvaginal, retro-uterine, intrapelvic balloon distention. This model would facilitate a better insight in the pathophysiology of $\mathrm{Fl}$ induced by obstetric trauma, which could change the treatment paradigm for Fl.

\section{2 | METHODS}

\section{1 | Subjects}

This study was conducted on 16 adult virgin female Wistar rats (Charles River Laboratories, Sulzfeld, Germany). The animals were divided in two groups: an experimental group $(n=10)$ and a control group $(n=6)$. The experimental group underwent transvaginal, retro-uterine, intrapelvic balloon distention and the control group consisted of un-operated healthy controls. The experiments were approved by the Dutch Committee for Animal Research local ethical committee, Maastricht University (AVD107002015187; DEC 2015-001).

\section{2 | Pressure calculation}

Using a conversion calculator, we calculated that $100 \mathrm{~mm} \mathrm{Hg}$ was equal to $0.013 \mathrm{~N} \mathrm{~mm}^{-2} .{ }^{23}$ The radius of the inflated balloon was $7.0 \mathrm{~mm}$. The contact surface was $7^{2} \times \pi=153.94 \mathrm{~mm}^{2}$. To imply a pressure of $100 \mathrm{~mm} \mathrm{Hg}$ over the surface of the balloon $\left(153.94 \mathrm{~mm}^{2}\right.$ ), we needed $0.013 \mathrm{~N} \mathrm{~mm}^{-2} \times 153.94 \mathrm{~mm}^{2}=2.05 \mathrm{~N}$.

\section{Key Points}

- There's a lack of basic knowledge regarding the pathophysiology of fecal incontinence (FI).

- We introduce a new safe and feasible animal model for fecal incontinence with transvaginal, intra-pelvic balloon distention combined with downwards pressure on the pelvic floor.

- This is a validated model for future research regarding the pathophysiology of $\mathrm{Fl}$, that can be used to optimize the treatment paradigm.

For a force of $2.05 \mathrm{~N}$ on the pelvic floor, we required a freely hanging weight of $2.05 / 9.81=0.21 \mathrm{~kg}$, which equals $200 \mathrm{~g}$.

\section{3 | Surgery}

Ten rats underwent transvaginal, retro-uterine, intrapelvic balloon distention. Pre-operative analgesia was administered using Buprenorphine (0.05 $\mathrm{mg} \mathrm{kg}^{-1}$ s.c.). Anesthesia was induced with 4\%-5\% Isoflurane (0.5 L per minute) in oxygen and maintained with $1.5 \%-3 \%$ Isoflurane. After successful anesthesia, the animals were placed in a supine position on a homeostatic warming blanket (Veterinary Technics/BDO-Medipass) to maintain a body temperature at $37^{\circ} \mathrm{C}$. Next, a midline incision was made. The omentum and small intestines were positioned cranially. The cecum was lateralized to optimize visualization of the uterus. A pediatric urinary catheter (Ch. 8, Rüsch Brillant Paediatric; Teleflex Medical Europe Ltd., Athlone, Ireland) was lubricated and inserted into the vagina and an incision was made on the dorsal part of utero-vaginal transition. The catheter was advanced through this incision and thereafter the balloon was inflated. The balloon had a maximum capacity of $3 \mathrm{~mL}$. After inflation and correct positioning of the balloon, a weight of $200 \mathrm{~g}$ was attached to the end of the catheter, which hung freely from the operating table inducing a compressive force of $100 \mathrm{~mm} \mathrm{Hg}$ on the pelvic floor (Figure 1). This force of $100 \mathrm{~mm} \mathrm{Hg}$ is comparable to the pressure on the human pelvis during vaginal childbirth (range $100-240 \mathrm{~mm} \mathrm{Hg}$ ). ${ }^{24,25}$ Both during the operation as during the pressure induction, the abdominal cavity was protected from drought. The balloon was deflated after one hour of inflation and the intrapelvic part of the catheter was cut and removed abdominally to reduce further damage to the vaginal wound. The abdominal organs were checked and inspected for signs of hemorrhage and tissue damage and subsequently closed in layers using 2.0 Vicryl (fascia) and 3.0 monocryl (skin) (Ethicon). Afterwards, the animal was allowed to recover.

The animals in the control group were only anesthetized for the same time period as the animals in the experimental group. Anesthesia was induced with $4 \%-5 \%$ Isoflurane ( $0.5 \mathrm{~L}$ per minute) in oxygen and maintained with $1.5 \%-3 \%$ Isoflurane. After successful anesthesia, the animals were placed in a supine position on a homeostatic warming blanket (Veterinary Technics/BDO-Medipass) to maintain a body temperature at $37^{\circ} \mathrm{C}$. Afterwards, the animal was allowed to recover. 

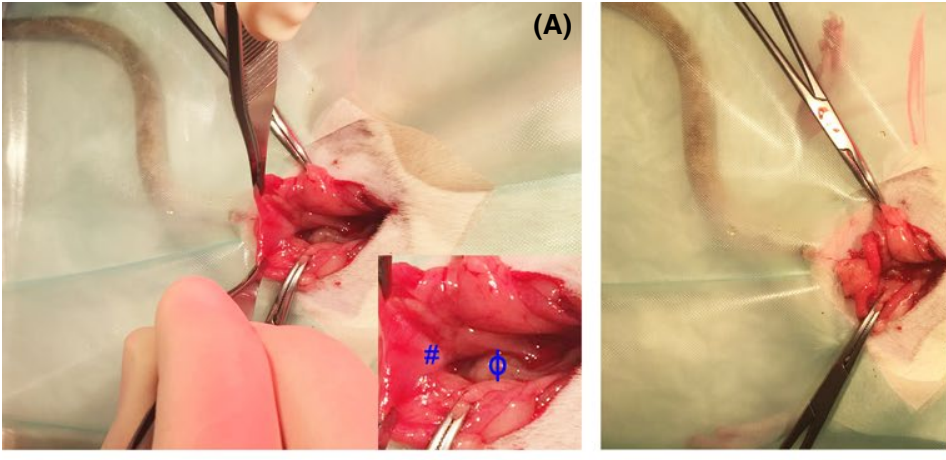

(D)
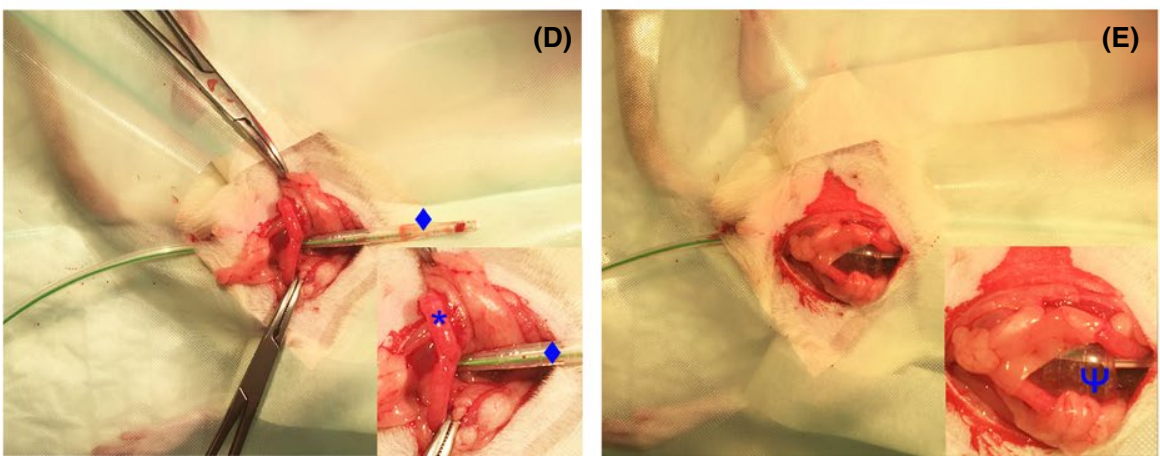

B)
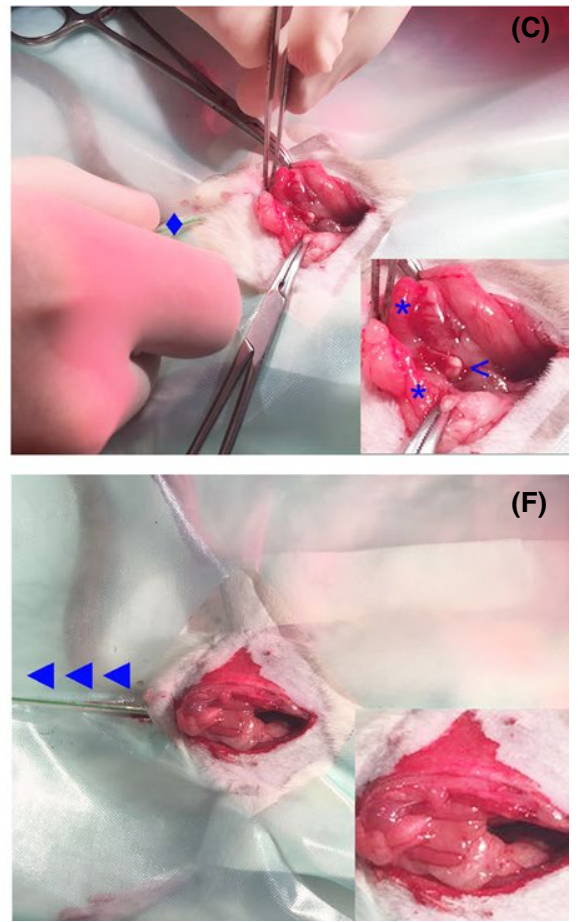

FIG URE 1 (A-F) demonstrates the details of the surgical procedures. \# the uterus; * the fallopian tubes; $\phi$ sigmoid; $\wedge$ the cervix; < the catheter tip at the cervix; the catheter tip; $\psi$ the inflated catheter; $\triangleleft \triangleleft$ the direction of the pressure induced on the pelvic floor

\section{4 | Recovery}

Postoperative pain medication was administered during 3 days follow-up using Caprofen 4-5 mg kg-1 s.c. Rats were pair housed and were allowed to recover for 3 days with ad libitum access to food and water and housed in a temperature-controlled room with a 12-hour light-dark cycle. The recovery period was meant to reduce the risk of surgical stress-induced defecation abnormality in operated animals. Besides, all animals were weighed daily to ensure no significant weight loss occurred. Wounds were inspected daily. All animals tolerated the procedure well and no side-effects or complications occurred.

\section{5 | Cage}

A large rat cage with dimensions of 61 by $43.5 \mathrm{~cm}$ in length and breadth, respectively, was divided in three compartments (approximately $20 \mathrm{~cm}$ ). Plates of five $\mathrm{mm}$ thick multiplex with a central doorway were used to create the compartments. The doorway allowed the rats to roam freely between the different compartments. The compartments consisted of area A, which contained the food and water, area $\mathrm{B}$, which contained the majority of nesting and play materials and area $\mathrm{C}$, which contained some nesting material (Figure 2). The division in three areas and allocation of the latrine area furthest from the food area is based on a previous study, which reported place preference for depositing fecal pellets as far away from the food area as possible. ${ }^{20}$ By placing nesting material in the latrine area, rats should be interested in both areas and spent an equal amount of time in both. The floor of all three compartments was covered with sawdust. The rats could roam freely in the cage with

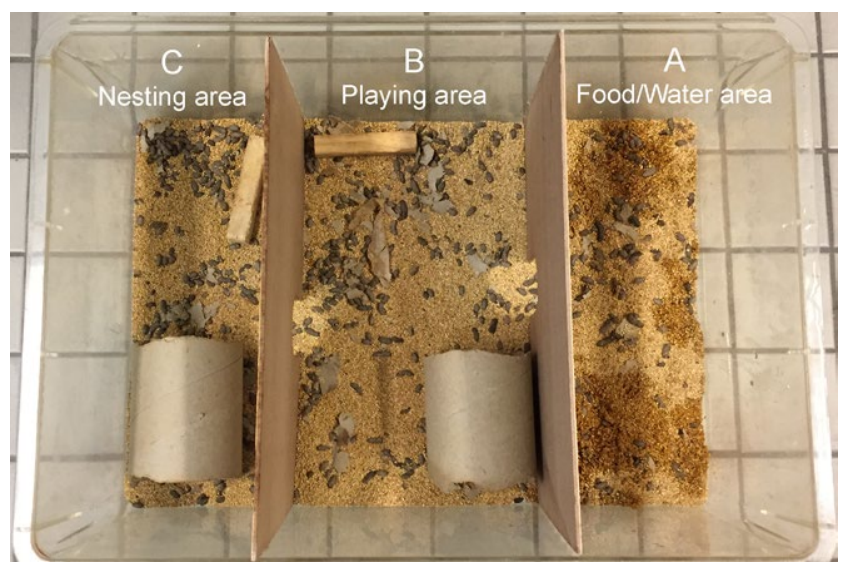

FIGURE 2 The cages were divided in three areas. This shows a typical distribution of the fecal pellets. Note: most pellets were found in the nesting area

a 12-hour light-dark cycle. Fecal pellets were counted per compartment every 24 hours, 5 days per week for 3 weeks. Notably, conventional cages were adapted and used for this proof of concept experiment. With this setting some difficulties occurred such as slight dislocation of dividing walls as it appears in the figure (Figure 2).

\section{6 | Statistical analysis}

Data are presented as standard error of the mean (SEM) for continuous variables, and count (percentage) for categorical variables. We calculated the Fecal Incontinence Index (FII) to assess the ratio of fecal pellets 
between the non-latrine areas and the total number of fecal pellets. ${ }^{20}$ A higher score represents more random distribution of feces outside the latrine area. The FII, total amount of fecal pellets and the proportion of fecal pellets per area were compared between the groups using repeated measures two-way (TIME and GROUP) ANOVA. The rule of outliers was applied for data which was $\geq 2 \mathrm{SE}$ deviant from the mean. Statistical significance was defined a $P<.05$. Data were analyzed using SPSS (version 23 for Windows, IBM New York, USA).

\section{3 | RESULTS}

The surgical procedure was well tolerated by the operated animals. No complications such as peritoneal infection, gastrointestinal tract injury or intestinal ischemia were observed during or after surgery.

Moreover, no behavioral abnormalities that could have been linked to internal organ damage were observed. At autopsy, macroscopic inspection of the abdominal organs did not indicate any sign of internal damage. Besides, there was no weight loss in both groups over the course of the study. Furthermore, there was no weight differences between the groups at baseline (experimental 195.4 g [SE = 61.8]; controls $194.3 \mathrm{~g}[\mathrm{SE}=79.3])(P=.091)$ and before sacrifice (experimental $211.3 \mathrm{~g}$ [SE $=66.8$ ]; controls $214.3 \mathrm{~g}$ [SE $=87.5])(P=.26)$.

During the study period of 14 days, the experimental group produced more fecal pellets per day (43.9 [SE $=0.63]$ ) compared to the control group (40.8 [SE =0.69]) (TIME effect $F=21.18, P<.001$ ) (Figure 3). Besides, the experimental group deposited more fecal pellets in the latrine area than the control animals $(F=2.15 ; P=.048)$. This difference occurred for both the number of pellets in the latrine area as for the proportion of pellets in the latrine area compared to the total number of pellets in the cage. However, in contrast with the expected effect, both groups deposited most of the fecal pellets in the nesting area (Figure 4). The proportion of fecal pellets in the nesting and latrine area compared to the total amount of fecal pellets remained stable during follow-up in both groups.

The FII was lower in the experimental group compared with the control group during follow-up (TIME by Group effect, $F=2.15$; $P=.048$ ), illustrating a change in defecation behavior after surgery (Figure 5). Animals in the experimental group deposited more fecal pellets in the latrine area compared to the controls suggesting that healthy animals do not have a place preference for defecation as previously suggested. ${ }^{20}$

\section{4 | DISCUSSION}

This study demonstrates that transvaginal, retro-uterine intrapelvic balloon distention is a safe and feasible model for induction of $\mathrm{Fl}$ in rats. Besides, the three-area cage model allows easy evaluation of defecation pattern and possible changes in defecation behavior after surgery. Animals in the experimental group deposited more fecal pellets in total (TIME effect) and dropped more fecal pellets in the latrine area compared to the healthy controls. The Fll was lower in the experimental group, suggesting a less random distribution of fecal pellets compared to the healthy controls (TIME by GROUP effect).

Animals in the experimental group produced more fecal pellets during follow-up compared with the control group. To our knowledge, only one previous study assessed defecation behavior in healthy rats too. ${ }^{20}$ They reported a mean total daily amount of fecal pellets of 43 (range 28-59), which is comparable to the total daily amount of fecal pellets of both our experimental and healthy groups. However, results should be compared with caution as their study had a limited follow-up of only 4 days. Our results showed a higher mean number of fecal pellets in both groups during the first week, which decreased as follow-up continued. The comparable amount of fecal pellets reported by Soetan et $\mathrm{al}^{20}$ might be due to a stress-component. It was previously reported that defecation frequency increases after inducing stress by placing rats in a different environment. ${ }^{26}$

Most fecal pellets were deposited in the nesting area by both the experimental and control group. Previous studies have shown a place preference far away from the feeding area for deposition of fecal pellets in rats. ${ }^{19,20}$ One study also divided the cages in three areas (food, nesting and latrine areas) but included only healthy rats. ${ }^{20}$ In contrast to our results, Soeten et al reported most fecal pellets were deposited in the latrine area during a follow-up of only 4 days. ${ }^{20}$ This difference in place preference is most likely related to differences in the experimental settings because our results after 4 days showed that both groups also deposited most fecal pellets in the nesting area. In a very recent study, the same group has replicated their finding using a welldesigned video-tracking behavioral study, showing that this model of

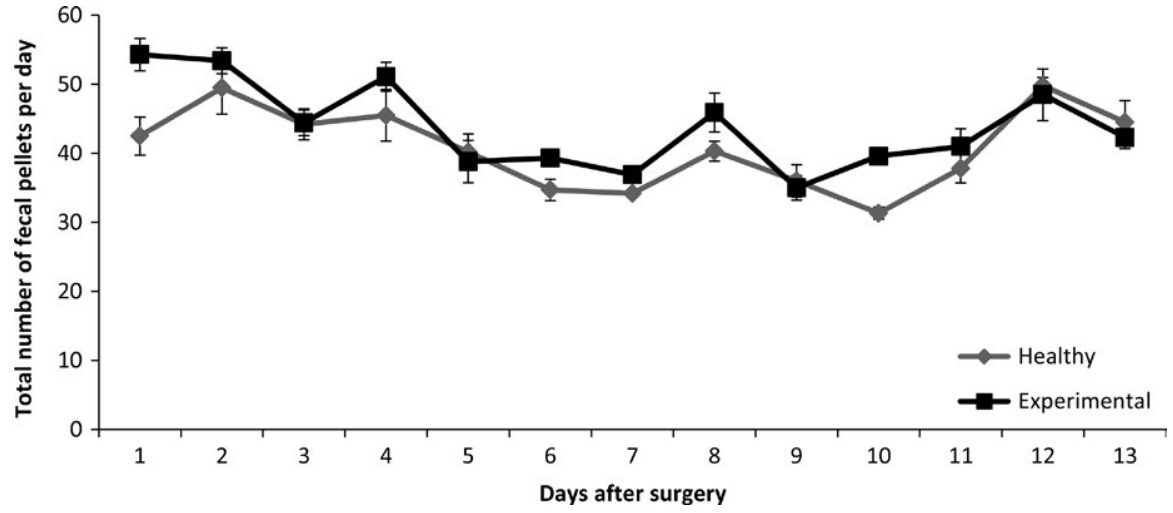

FIGURE 3 Total amount of fecal pellets produced per day. The experimental group produced more fecal pellets per day according to repeated measures two-way ANOVA (TIME effect $F=21.18, P<.001$ ). Values are presented as standard error of mean (SEM) 

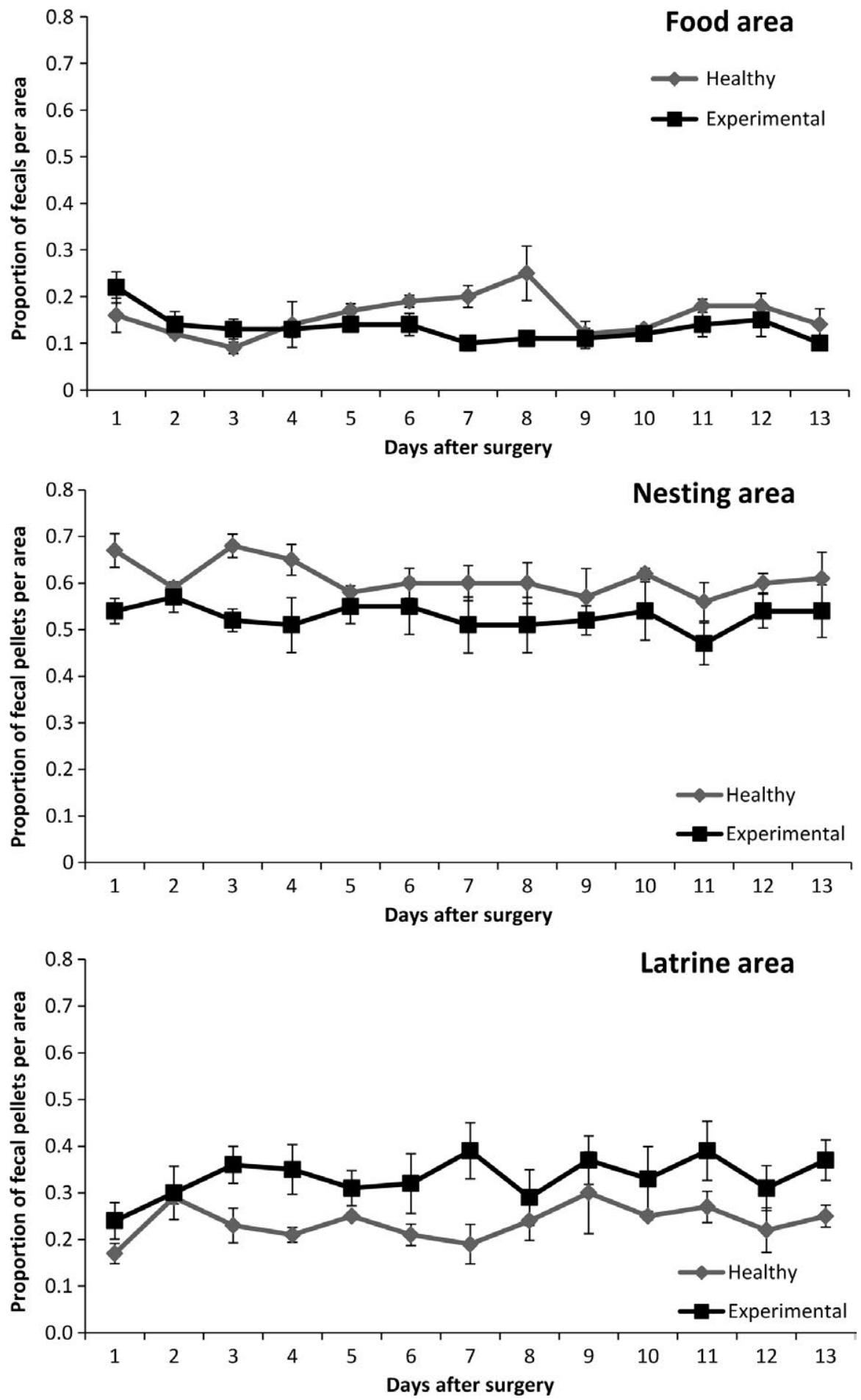

FIGURE 4 Proportion of fecal pellets per area compared to the total amount of fecal pellets in the cage. The experimental group deposited more fecal pellets in the latrine area compared to the control animals $(F=2.15 ; P=.048)$. Values are presented as standard error of mean (SEM)

pudendal neuropathy affects continence in $32 \%$ of rats. ${ }^{27}$ There were several differences in the experimental setting between our study and Soetan et $\mathrm{al}^{20}$ Firstly, we used larger cages to allow the animals more movement freedom. Secondly, our cages were divided using dark multiplex walls instead of see-through Plexiglas walls. Moreover, we pair housed the animals instead of solitary housing. Finally, we also placed nesting material in the latrine area instead of only placing it in the nesting area. We hypothesized that if place preference was related to a behavioral mechanism to deposit feces as far away from the food as possible, nesting material should not be of influence. By placing nesting material in the latrine area, rats should be interested in both areas and spent an equal amount of time in both. Due to logistical limitations we did not track the time the animals spent in each area. This limitation prevents a correlation between time spent in each area and amount of fecal pellets deposited in that area.

In contrast with what we expected, the Fecal Incontinence Index was lower in the experimental group during follow-up indicating that the experimental group deposited less fecal pellets outside the 


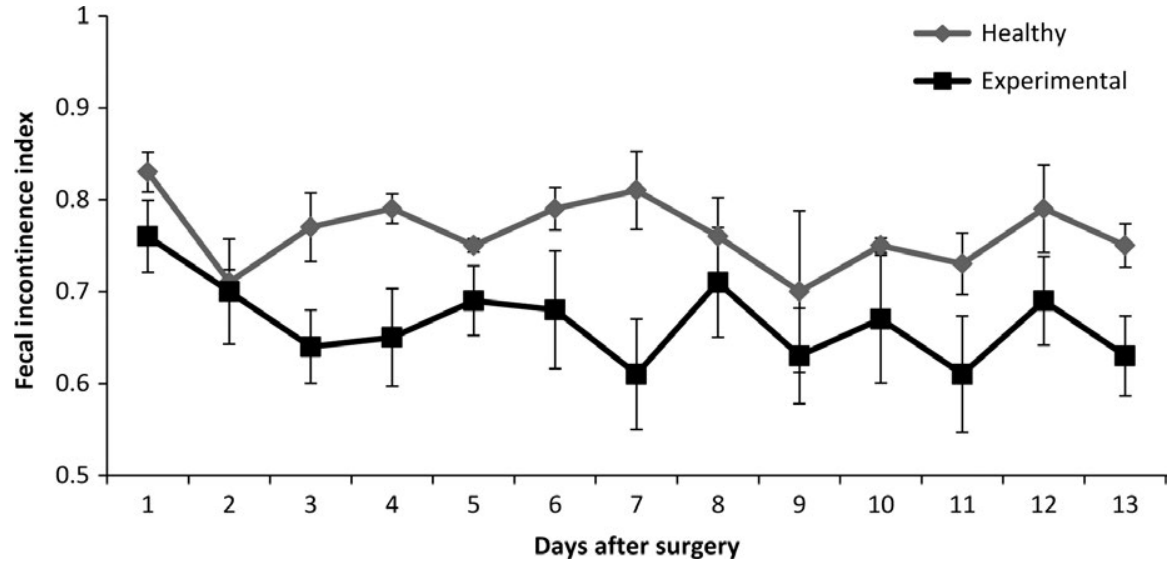

FIGURE 5 Fecal Incontinence Index. The experimental group had a significant lower FIl according to two way repeated measures ANOVA ( $F=2.15 ; P=.048$ ). Values are presented as standard error of mean (SEM) latrine area compared to the healthy controls. The healthy controls deposited more fecal pellets in the non-latrine areas compared to the experimental group indicating a more random distribution in healthy animals. It is hypothesized that although rats do not display a place preference for depositing fecal pellets, an anxiety component after surgery cannot be excluded. Feeding and coprophagic behavior can be excluded as a potential cause as all animals had unrestricted access to food and water. Also, it has been previously shown that the distribution of feces is not influenced by collection of pellets for coprophagic purposes. $^{20}$

This work shows that only $30 \%$ of our rats develop incontinence and therefore the authors new method may prove superior in the future $^{27}$ For further validation of this method, we suggest histological studies on acute and long-term effects of transvaginal, retro-uterine balloon distention on the muscle mass of the anal sphincter complex. A previous study reported loss of muscle mass of the external anal sphincter after application of a comparable technique. ${ }^{16}$ Loss of muscle mass 1 week after balloon distention was comparable to the muscle loss 1 week after bilateral pudendal nerve crush lesions. However, loss of external anal sphincter muscle mass was recovered 4 weeks after balloon distention. Recovery of neural damage in rats has previously been reported by studies in the field of experimental neuronal damage models. ${ }^{28-30}$ They showed that neuroplasticity in the subcortical regions in rats allows recovery from stroke and spinal cord injuries through neural remodeling. The immunohistochemical analysis of this study was limited by the absence of an evaluation of the anal sphincter complex. Moreover, the effect of environmental factors such as stress or anxiety on defecation behavior yet to be verified in this animal model.

This study demonstrated that transvaginal, retro-uterine, intrapelvic balloon distention is a safe and feasible animal model for induction of fecal incontinence simulating the human physiologic impact of labor. This is a valid model for future research regarding the pathophysiology of $\mathrm{FI}$, which can be used to optimize the treatment paradigm and explore novel therapeutic approaches.

\section{CONFLICT OF INTEREST}

PJ, SB, and JM received a non-restrictive research grant from Medtronic.

\section{AUTHOR CONTRIBUTIONS}

PJ, SB, JM, LS, NB, YT, and AJ designed the study; PJ and AJ performed the surgeries and collected the data; PJ, SB, YT, and AJ analyzed and interpreted the data; PJ, SB, JM, LS, NB, YT, and AJ drafted the manuscript; LS, NB, YT, and AJ supervised the study. All authors gave final approval of the final version.

\section{ORCID}

A. Jahanshahi iD http://orcid.org/0000-0002-7451-3461

\section{REFERENCES}

1. Miner PB Jr. Economic and personal impact of fecal and urinary incontinence. Gastroenterology. 2004;126(1 Suppl 1):S8-S13.

2. Frieling T. [Incontinence - etiology, diagnostics and therapy]. Deutsc Med Wochenschr. 2016;141:1251-1260. Stuhlinkontinenz: Ursache, Diagnostik und Therapie.

3. Moya P, Arroyo A, Lacueva J, et al. Sacral nerve stimulation in the treatment of severe faecal incontinence: long-term clinical, manometric and quality of life results. Tech Coloproctol. 2014;18: 179-185.

4. Alavi K, Chan S, Wise P, Kaiser AM, Sudan R, Bordeianou L. Fecal incontinence: etiology, diagnosis, and management. J Gastrointest Surg. 2015;19:1910-1921.

5. Donnelly V, Fynes M, Campbell D, Johnson H, O'Connell PR, O'Herlihy C. Obstetric events leading to anal sphincter damage. Obstet Gynecol. 1998;92:955-961.

6. Snooks SJ, Henry MM, Swash M. Faecal incontinence due to external anal sphincter division in childbirth is associated with damage to the innervation of the pelvic floor musculature: a double pathology. $\mathrm{Br} J$ Obstet Gynaecol. 1985;92:824-828.

7. Fitzpatrick M, O'Brien C, O'Connell PR, O'Herlihy C. Patterns of abnormal pudendal nerve function that are associated with postpartum fecal incontinence. Am J Obstet Gynecol. 2003;189: 730-735.

8. Zutshi M, Tracey TH, Bast J, Halverson A, Na J. Ten-year outcome after anal sphincter repair for fecal incontinence. Dis Colon Rectum. 2009;52:1089-1094.

9. Chapman AE, Geerdes B, Hewett P, et al. Systematic review of dynamic graciloplasty in the treatment of faecal incontinence. Br J Surg. 2002;89:138-153.

10. Matzel KE, Madoff RD, LaFontaine $L$, et al. Complications of dynamic graciloplasty: incidence, management, and impact on outcome. Dis Colon Rectum. 2001;44:1427-1435. 
11. Melenhorst J, Koch SM, Uludag O, van Gemert WG, Baeten CG. Sacral neuromodulation in patients with faecal incontinence: results of the first 100 permanent implantations. Colorectal Dis. 2007;9:725-730.

12. Wexner SD, Coller JA, Devroede G, et al. Sacral nerve stimulation for fecal incontinence: results of a 120-patient prospective multicenter study. Ann Surg. 2010;251:441-449.

13. Duelund-Jakobsen J, Lehur PA, Lundby L, Wyart V, Laurberg S, Buntzen S. Sacral nerve stimulation for faecal incontinence-efficacy confirmed from a two-centre prospectively maintained database. Int $J$ Colorectal Dis. 2015;31:421-428.

14. Janssen PT, Kuiper SZ, Stassen LP, Bouvy ND, Breukink SO, Melenhorst J. Fecal incontinence treated by sacral neuromodulation: long-term follow-up of 325 patients. Surgery. 2017;161: 1040-1048.

15. Evers J, Devane L, Carrington EV, et al. Reversal of sensory deficit through sacral neuromodulation in an animal model of fecal incontinence. Neurogastroenterol Motil. 2016;28:665-673.

16. Healy CF, O'Herlihy C, O'Brien C, O'Connell PR, Jones JF. Experimental models of neuropathic fecal incontinence: an animal model of childbirth injury to the pudendal nerve and external anal sphincter. Dis Colon Rectum. 2008;51:1619-1626; discussion 26.

17. Peirce C, Healy CF, O'Herlihy C, O'Connell PR, Jones JF. Reduced somatosensory cortical activation in experimental models of neuropathic fecal incontinence. Dis Colon Rectum. 2009;52: 1417-1422.

18. Tadayyon B, Lutwak L. Role of coprophagy in utilization of triglycerides, calcium, magnesium and phosphorus in the rat. $J$ Nutr. 1969;97:243-245.

19. Kimchi T, Terkel J. Magnetic compass orientation in the blind mole rat Spalax ehrenbergi. J Exp Biol. 2001;204:751-758.

20. Soetan BK, O'Connell PR, Jones JF. Behavioural studies of faecal continence in the rat. Ir J Med Sci. 2014;183:629-632.

21. Congilosi SM, Johnson DR, Medot M, et al. Experimental model of pudendal nerve innervation of a skeletal muscle neosphincter for faecal incontinence. Br J Surg. 1997;84:1269-1273.
22. Sievert KD, Bakircioglu ME, Tsai T, Nunes L, Lue TF. The effect of labor and/or ovariectomy on rodent continence mechanism-the neuronal changes. World J Urol. 2004;22:244-250.

23. DataQualityApps. Conversion-calculator for measurement units 2016; 2016. Available from: https://www.convert-measurement-units.com/ about-us.php.

24. Blaivas JG, Labib KL, Bauer SB, Retik AB. Changing concepts in the urodynamic evaluation of children. J Urol. 1977;117:778-781.

25. Rempen A, Kraus M. Measurement of head compression during labor: preliminary results. J Perinat Med. 1991;19:115-120.

26. Prut $L$, Belzung $C$. The open field as a paradigm to measure the effects of drugs on anxiety-like behaviors: a review. Eur J Pharmacol. 2003;463:3-33.

27. Devane LA, Lucking E, Evers J, et al. Altered defaecatory behaviour and faecal incontinence in a video-tracked animal model of pudendal neuropathy. Colorectal Dis. 2017;19:0162-0167.

28. Dhillon RS, Parker J, Syed YA, et al. Axonal plasticity underpins the functional recovery following surgical decompression in a rat model of cervical spondylotic myelopathy. Acta Neuropathol Commun. 2016;4:89.

29. Garcia-Alias G, Truong K, Shah PK, Roy RR, Edgerton VR. Plasticity of subcortical pathways promote recovery of skilled hand function in rats after corticospinal and rubrospinal tract injuries. Exp Neurol. 2015;266:112-119.

30. Xin $\mathrm{H}$, Katakowski M, Wang F, et al. MicroRNA cluster miR-17-92 cluster in exosomes enhance neuroplasticity and functional recovery after stroke in rats. Stroke. 2017;48:747-53.

How to cite this article: Janssen PTJ, Breukink SO, Melenhorst J, et al. Behavioral outcomes of a novel, pelvic nerve damage rat model of fecal incontinence. Neurogastroenterol Motil. 2018;30:e13242. https://doi.org/10.1111/nmo.13242 